charges passed involves the disappearance of one atom of oxygen or nitrogen respectively.

4. For helium (continually purified by carbon in liquid air), a current flowed but no disappearance of gas took place.

Thus with hydrogen at an initial pressure of 2.5 $\mathrm{mm}$., in $21 \mathrm{~min}$. the pressure fell to $0.03 \mathrm{~mm}$. The current through the glass (at 480 volts) was variable (6 to 16 m.a.) Assuming $\mathrm{H}^{+}$as carrier, then, from the electrical quantity, $1 \cdot 16$ c.c. at N.T.P. should have disappeared. Actually 2.05 c.c. disappeared. With initial pressure $0.057 \mathrm{~mm}$. the current was 0.5 to 0.1 m.a. (500 volts), and the estimated disappearance was $22.7 \times 10^{-3}$ c.c. at N.T.P. The actual disappearance was $41 \times 10^{-3}$ c.c.

Experiments carried out on the conduction of glass and quartz at temperatures such as those used in the above experiments showed that the conductivity was considerable and the mechanism largely electrolytic. Only a relatively small quantity of the gas that had disappeared was recovered on heating, and the electrical action was not reversible (sodium was introduced on reversing). Experiments carried out to test whether the gas passed through the glass walls and could be collected have, up to the present, given negative or inconclusive results.

The non-disappearance of helium shows that the action is not an accelerated diffusion through the glass pores, for, in that case, helium should pass through about twenty times as quickly as hydrogen.

The action appears to arise from an electrolytic decomposition of the glass which probably results, in the case of hydrogen, in the formation of water which penetrates deep into the glass structure.

With mercury discharges gas is usually brought out of the walls.

The above actions are probably of fundamental significance in most phenomena of 'clean up' or gas disappearance into glass walls.

Trinity College,

Cambridge, April 11.

\section{Rare Fishes in the North Sea.}

There are a good many North Sea fishes which never pass their whole lives in that sea, but only enter it for limited periods, in quest of spawninggrounds or of food. Amongst these are several important species, such as the hake and the halibut, the mackerel and the tunny; and others also of less importance, such as the gurnards, the anchovy, the horse-mackerel, and the monk or angler (Lophius). While all of these arrive in sufficient quantity to be more or less important to the fisherman, there are others which come in small shoals or as individual stragglers, and so come to be considered as rare and unusual occurrences. It happens that within the last couple of years or so some of these casual visitors have been unusually plentiful, and have attracted the attention of the fishermen.1

Among these recent visitors has been a number of sharks, of more or less uncommon species. The Thresher shark (Alopias) is one of these; another, and a greater stranger, is the great Basking Shark of Atlantic waters (Selache maxima). Another stranger to the North Sea is the Six-gilled Shark (Hexanchus or Notidanus griseus, L.), which has its home in the Mediterranean and neighbouring parts of the Atlantic, but has of late occurred in our home waters in quite unusual abundance. It has been caught especially on the Viking Bank, to the westward of the deep

1 Cf. Der Fischerbote (Hamburg), p. 487, 1927 ; p. 126, 1928.

No. 3053 , Vor. 121]
Norwegian Channel, and in such numbers as to become of almost regular occurrence in the fishmarkets of Germany, where these and other sharks are in demand for food and fetch very good prices.

Even more remarkable perhaps than these is a long succession of captures of Ray's Bream, a fish of remarkable and striking appearance, which up to very lately had been but seldom recorded from the North Sea. Of late it has been taken in the English Channel and on the Viking Bank; and specimens have been caught or cast ashore in a large number of places all along the east coast of Great Britain from Cromer to the Dornoch Firth. One was lately caught in a flounder net on the Swedish coast of the Ore Sound; and there is an earlier record so far east as the Pomeranian coast of the Baltic.

In the past few months there have also been caught on the Viking Bank by German steam-trawlers certain other very rare species :

1. The so-called 'Devil-fish' (Epigonus telescopus, Risso ; formerly wrongly named Pomatomus). This is a perch-like fish never before recorded from the North Sea; its true home is in the southern Atlantic, for example, near St. Helena. It is a dark-coloured fish, with enormous shining or luminous eyes. Our North Sea specimen was $57 \mathrm{~cm}$. long, and was trawled at the very considerable depth of 230 metres.

2. The Blackfish (Centrolophus pompilus, Risso) belongs to the family Stromateidæ, and has a certain outward resemblance to some of the flatfishes. A specimen $(53 \mathrm{~cm}$. long) was caught recently in $59^{\circ} 20^{\prime} \mathrm{N}$., $3^{\circ} \mathrm{E}$.; and another a couple of years ago, on the Danish side of the Cattegat. It has been recorded before from the North Sea, but by no means often; it is an Atlantic fish, going as far south as Madeira. An allied species (C. britannicus) has occasionally been captured in the western part of the Channel.

3. The Snipefish, or Trumpet-fish (Centriscus or Macrorhamphus scolopax, L.), is a fish of curious appearance, with a small toothless mouth on a long tubular snout, well known in the Mediterranean. It has been observed a few times on the Cornish and on the Irish coasts, and on one previous occasion in the North Sea, near Arendal on the south coast of Norway.

All these rare Atlantic fishes come from the deep water of the Viking Bank ; and it would seem necessary to suppose, in order to account for their presence there, that they had been transported by a submarine current from the Atlantic rounding the plateau of the northern North Sea and making its way into the Norwegian Channel. But while Ray's Bream, the Devil-fish, and the Blackfish may all be considered deep-water forms, and might well have come by such a deep-water under-current, it is somewhat remarkable that the Snipefish is known to prefer soft ground near to the coast in waters of only moderate depth -at least in its home in the Mediterranean.

Hamburg.

E. Ehrenbaum.

\section{Stark Effect and Series Limits.}

THE treatments of the Stark effect found in the literature concern themselves chiefly with the behaviour of atoms in the lower quantum states, a problem to which the theory of perturbations can be applied. Consideration of the effect of the external electric field on highly excited atoms necessitates the discussion of the complete equations, in particular with regard to the existence of conditionally periodic orbits. The investigation which we have carried out gives a negative upper limit for the energy of quantised 